\title{
FAMÍLIA E ENVELHECIMENTO: UM ESTUDO SOBRE AS RELAÇÕES ENTRE AVÓS E NETOS
}

\section{FAMILY AND GETTING OLD: A STUDY ON THE RELATION BETWEEN GRANDPARENTS AND GRANDCHILDREN}

\author{
Cássia Fernanda Araújo Louzeiro ${ }^{1}$ Ana Beatriz Rocha Lima ${ }^{2}$
}

\begin{abstract}
RESUMO: Trata-se de uma revisão narrativa de literatura que apresenta como objetivo compreender as relações entre avós e netos no âmbito familiar e social, investigando vínculos afetivos entre avós e netos, demostrando os papéis desempenhados por esses idosos no contexto familiar, a percepção de como são vistos dentro e fora da família, apontando benefícios que essas relações oferecem. Esse estudo utilizou os descritores "relações entre avós e netos", "envelhecimento", "relações familiares", "idosos no meio familiar", "papel do idoso" para a busca nas seguintes bases de dados: Google Acadêmico, PEPSIC, SciELO, BVS-Biblioteca Virtual da Saúde, entre os anos de 2000 a 2015. Observa-se uma mudança no perfil etário da população brasileira, em que há um crescimento elevado do público de idosos no país. A família compõe um campo fundamental na vida do idoso, uma vez que este tem uma diminuição da sua rede de apoio social. Portanto, cabe à família disponibilizar informação e apoio à promoção de relações sociais agradáveis, propiciar independência e autonomia entre as gerações, agir em momentos de crise e propor apoio psicológico. O aumento da longevidade permite que os idosos tenham uma convivência mais duradoura entre três ou mais gerações, conduzindo os idosos a se envolverem mais com a vida familiar. O convívio frequente entre avós e netos resulta no fortalecimento dos vínculos, até porque a relação intergeracional traz boas vantagens. Os idosos melhoram a qualidade de vida, fisicamente se sentem mais ativos, se preocupam com a saúde para que possam garantir o acompanhamento do crescimento das crianças.
\end{abstract}

PALAVRAS-CHAVE: Família; Netos; Avós; Transgeracionalidade; Avosidade.

ABSTRACT: This is a narrative literature review which has the objective of understanding the relationships between grandparents and grandchildren in the family and social context, investigating affective bonds between grandparents and grandchildren, showing the roles played by these elders in the family context, the perception of how they are seen within and outside the family and pointing benefits that these relationships offer. This study used the entries "relationship between grandparents and grandchildren", "aging", "family relations", "the elderly in the family" and "elderly role" for the search in the following databases: Google Scholar, PEPSIC, SciELO, BVSBiblioteca Virtual da Saúde, analyzing publications dated from 2000 to 2015 . There has

\footnotetext{
${ }^{1}$ Egressa do Curso de Psicologia (ano de conclusão 2016) da Universidade Ceuma. São Luís MA, Brasil. Email: fernandaa.louzeiro@gmail.com

2 Orientadora, Mestre em Educação e Especialização em Psicologia da Infância pela Universidade do Itajaí/SC. Doutora em Psicologia Social, do Trabalho das Organizações (PSTO) pela Universidade de Brasília/DF. Docente do curso de Psicologia da Universidade Ceuma. E-mail: anabeatriz.rochalima@gmail.com
} 
been a change in the age profile of the population: there is a high growth of the elderly population in the country. The family plays an essential role in the life of the elderly because they have a decrease in their social support network. So, it is up to the family to provide information and support for the promotion of pleasant social relations, foster independence and autonomy between generations, act in times of crisis and offer psychological support. Increased longevity allows seniors to have a more lasting coexistence with three or more generations, leading the elderly to become more involved with family life. Frequent interaction between grandparents and grandchildren results in the strengthening of ties because the intergenerational relationship brings good benefits. Seniors improve the quality of life, feel more physically active, and care about health so that they can ensure the monitoring of the growth of children.

KEYWORD: Family; Grandchildren; Grandparents; Transgenerationality; Grandparenthood.

\section{INTRODUÇÃO}

Observa-se uma mudança no perfil etário da população brasileira, em que há um crescimento elevado do público de idosos no país. De acordo com o Instituto Brasileiro de Geografia e Estatística (IBGE) (2012), estima-se que em 2020, o Brasil terá a $6^{\text {a }}$ maior população idosa do planeta, somando 23,5 milhões dos brasileiros (BRASIL, 2003). A longevidade não é o único componente para avaliar a propagação de um envelhecimento benéfico. Envelhecer bem envolve múltiplos fatores, incluindo fatores individuais, psicológicos, biológicos e sociais. Embora o contentamento subjetivo seja o componente mais importante para avaliar o "sucesso" no processo de envelhecimento. Este envelhecimento bem-sucedido assemelha-se a um princípio organizacional, podendo ser alcançado, estabelecendo-se metas pessoais realistas no percurso da vida.

Segundo Néri (2004), o progresso da interação social entre esses idosos, o cuidado com a saúde e o envolvimento nos grupos sociais contribuem para o aumento mundial do número de idosos mais ativos e saudáveis. Fato que faz ultrapassar o número de idosos com alguma doença, que se sentem incapazes, ou que morrem cedo. Nesse sentido, Néri e Yassuda (2012) afirmam que a Psicologia do Envelhecimento tem muito a contribuir, pois focaliza nas questões cognitivas, afetivas e sociais o sucesso do envelhecimento. Tais como as alterações motivacionais, interesses, atitudes e valores são característicos dos anos da fase adulta e da terceira idade para que possam ser bem vividos. Essa área da Psicologia tem como foco de estudo também os processos e as condições complexas que afetam o desempenho psicológico dos idosos. 
As autoras supracitadas acrescentam, ainda, que a Psicologia do Envelhecimento estuda determinados aspectos relacionados ao processo de envelhecimento como as relações sociais e apoio social; papéis de gênero; personalidade; sabedoria; criatividade; fragilidade; dependência e declínio; violência; abuso e vitimização que estão diretamente associados quando se estuda idoso e família. Para Néri e Yassuda (2012), a família compõe um campo fundamental na vida do idoso, uma vez que este tem uma diminuição da sua rede de apoio social. Portanto, cabe à família disponibilizar informação e apoio à promoção de relações sociais agradáveis, propiciar independência e autonomia entre as gerações, agir em momentos de crise e propor apoio psicológico.

Desta forma, é interessante sistematizar estratégias que visem intervir positivamente para a convivência familiar, que possam assegurar à pessoa idosa que vivencia o seu papel de avô ou avó exprimir relações afetivas com seus netos, conhecer estratégias de enfrentamento em relações conflituosas com os filhos ou elucidar ainda os estereótipos e obstáculos que um idoso enfrenta. Segundo Kipper e Lopes (2006), quando os filhos tornam-se pais, esses avós tendem a redefinir um novo lugar dentro meio familiar. Consequentemente, altera-se a imagem que esses filhos representam socialmente, assim, construindo novos vínculos com os netos, pois essas crianças representam uma continuação genética desses idosos.

Na perspectiva de Jung (2009), tornar-se avô pode cooperar para o processo de individuação do idoso, fundamental para a saúde e bem-estar, pois a individuação (que difere do individualismo) consiste no estímulo da criação de condições para que o indivíduo desperte o melhor de si próprio e do outro. Constantemente, isso faz com que este saia da solidão e experimente uma convivência abrangente e coletiva, por estar mais próximo do meio social e/ou familiar. Sobretudo, permanecendo na sua individualidade, visto que a individuação significa aproximar o mundo da pessoa e não excluí-la deste. Com o nascimento dos netos, o familiar idoso tende a ocupar novas posições dentro da família. Rodrigues (2013) afirma que os avós, há muito tempo, têm sido considerados como suporte social para suas famílias, desde a disponibilidade para cuidar dos netos até a servir como recurso financeiro para os filhos.

Numa dinâmica de entender o elo entre essas gerações, Zimerman (2000) afirma que há uma transferência de crenças, valores, conduta e cultura, de uma geração para outra, fatores que caracterizam o aspecto transgeracional, uma realidade de 
qualquer família, independente de raça, religião e/ou status social. Assim, o presente estudo tem como objetivo compreender e investigar as relações entre avós e netos no âmbito familiar e social. Numa perspectiva de analisar os vínculos afetivos existentes com os netos, demonstrar quais papéis esses idosos desempenham e como ele é visto dentro e fora da família, inclusive quais benefícios essas relações oferecem.

\section{REVISÃO DE LITERATURA}

\subsection{O processo de envelhecimento}

Para Ferrari (1999 apud ASSIS, 2005), o envelhecimento humano trata-se de um processo natural, gradativo e contínuo. Para cada indivíduo, a experiência de envelhecer é diferenciada, pois o envelhecimento é definido por fatores biológicos, psicológicos, cronológicos, sociais e culturais. A interação desses aspectos é estabelecida conforme circunstâncias, nas quais integram o meio cultural que o sujeito está incluído. Essas situações relativas ao processo de envelhecimento envolvem questões históricas, políticas, econômicas, geográficas e culturais, que executam diversas exposições sociais a respeito da velhice. Existe uma relação acerca da concepção de velhice propriamente dita, que se faz presente em uma sociedade e as posições ou papéis sociais que os indivíduos ocupam na sociedade quando estão envelhecendo.

Para Moraes et al. (2010), as peculiaridades de cada indivíduo transformam-se ao longo do tempo, ficando mais abundante no momento em que se analisam as duas proporções, a psíquica e a biológica, agregadas ao âmbito familiar e social, isto é, referem-se à plenitude da pessoa. O desenvolvimento sucessivo do envelhecimento é, desta forma, integralmente particular, mutável, cujo êxito se dá gradativamente, desde o tempo de criança. Uma velhice considerada próspera é resultante de uma trajetória de vida exitosa. A dimensão social e afetiva assume um papel fundamental na velhice. Idosos relatam voltar no tempo quando na presença dos netos, em situações nas quais são convidados a lembrar de suas experiências ao longo da vida, em especial, quando lembram-se de sua própria infância. Dessa forma, os netos operam um essencial significado no cotidiano dos avós, essa união torna-se crucial para os sujeitos que estão envelhecendo (OLIVEIRA et al., 2010). 


\subsection{O IDOSO E A FAMÍLIA}

A família tem significado importante em todas as etapas da vida do ser humano e, na fase da velhice, isso não é diferente. Conforme se envelhece, a família se modifica, principalmente, altera-se o lugar de cada integrante inserido nela. A família, para um idoso, por exemplo, é caracterizada pelos seus filhos, netos, bisnetos e outros membros com idade inferior a dele (ZIMERMAN, 2000). De acordo com Rabelo e Néri (2015), a família se organiza diante dos papéis que são concedidos ao idoso e da ordenação de posições dos outros membros. De modo que, os formatos de relações são estabelecidos no decorrer da vida familiar. Zimerman (2000) menciona que é interessante analisar os comportamentos de cada membro da família do idoso, descrevendo sete tipos de famílias: (1) família suficientemente sadia; (2) família simbiótica; (3) família dissociada ou dividida; (4) família narcisista; (5) família com perdas de limites; (6) família depressiva; (7) outros tipos.

A família suficientemente sadia é aquela em que a harmonia predomina, há uma relação tranquila entre as pessoas, onde os pais servem de exemplo para os filhos, havendo uma demarcação de lugares e papéis de cada membro da família. A família simbiótica é caracterizada, aparentemente, por uma ligação de amor entre todos, mas, na verdade, trata-se de uma ausência de autonomia de conquistar o seu próprio espaço, vivem juntos de uma maneira excessiva, possibilitando aos pais infantilizarem um ou mais filhos (ZIMERMAN, 2000). A família dissociada ou dividida é aquela que não tem uma dinâmica de integração entre pais, filhos, netos e avós. A família narcisista é identificada pelos comportamentos dos membros de acreditarem sempre que são os donos da razão, que possuem os melhores valores e costumam ter uma postura de arrogantes em relação às outras pessoas. A família com perdas de limites sinaliza que pode haver um dano na estrutura da família sadia, caso não haja adequação de limites, manutenção da hierarquia de papéis e posições de cada membro (ZIMERMAN, 2000).

A família depressiva é caracteriza por uma prevalência da tristeza, pessimismo generalizado e apatia. E, por fim, existem outros tipos de famílias que se configuram em: obsessiva (perfeccionismo, controle exacerbado e intolerância); fóbica (receio em tomar iniciativas e vivenciar situações novas); paranoide (desconfiança, sensibilidade, provocações e criações de caso); sadomasoquista (maus tratos, humilhações recíprocas, alternância de amor e ódio); hipocondríaca (uso abusivo de remédios, busca de possíveis doenças, ida excessiva ao médico e para fazer exames laboratoriais) 
(ZIMERMAN, 2000). Cada família tem a sua dinâmica específica de funcionamento, que poderá facilitar ou dificultar a convivência com seu familiar idoso. Algumas dificuldades observadas no relacionamento dentro da família referem-se à falta de comunicação, problemas relacionados a visão, audição, depressão, distúrbios do sono, excesso de medicação, paranoia, problemas de memória, dificuldades de as pessoas se colocarem no lugar do idoso. Habitualmente, os jovens e os filhos não compreendem que o idoso pertence a uma época diferente do momento atual, ou ainda tem dificuldade em se locomover, ou seja, tem outro ritmo de vida (ZIMERMAN, 2000).

\subsection{TRANSGERACIONALIDADE}

A transgeracionalidade ou transmissão psíquica geracional caracteriza-se por uma metapsicologia psicanalítica, especificamente definida como pulsão, narcisismo, identificação, trauma, recalcamento, denegações, significantes, fantasmas, dentre outros presentes entre as gerações. Essa transmissão acontece decorrente de processos psíquicos inconscientes de forma subjetiva através da linguagem, símbolos, ou daquilo que é real e imaginário dentro das relações geracionais da família (REHBEIN; CHATELARD, 2013).

A transmissão psíquica geracional se remete também à inserção do sujeito naquilo que é simbólico, ou seja, as palavras que ele aprende, estruturando a subjetividade e desenvolvendo psiquicamente tudo aquilo que é herdado, potencializando ainda o envolvimento familiar e sua relação com seu semelhante. Para a Psicanálise, a transgeracionalidade aborda questões psíquicas do grupo familiar, no que diz respeito à relação do sujeito com seu semelhante, caracterizando uma elaboração de intersubjetividade (REHBEIN; CHATELARD, 2013).

O indivíduo responsável pela herança divide-se entre o fim de si próprio e a continuação de ser uma conexão de intersubjetivação familiar, a qual está submetido. Nesse contexto, é possível que esse indivíduo transmita representações de afetos e fantasias, como objetos psíquicos (ALMEIDA, 2008). Porém, o idoso, como um elemento inserido no campo familiar e social, ou seja, geracional, pode representar uma figura mal compreendida, por ser de uma geração diferente da dos filhos e dos netos e, ao mesmo tempo, constituir a mesma matriz geracional. Zimerman (2000) enfatiza a necessidade de romper com a passagem de condutas distorcidas às novas gerações, ou seja, parar de associar o idoso somente a morte, doença, declínio mental e físico. A 
família deve transmitir psiquicamente aos netos, condutas respeitosas para que quando estes se tornem idosos sejam recebidos por uma geração mais positiva e acolhedora, ou seja, tenham representações pelas quais eles mesmos passaram. Assim, o aspecto transgeracional é importante, pois sinaliza que há diálogo entre as gerações dentro da família, rompendo com supostas dificuldades apontadas no convívio com a pessoa idosa (ZIMERMAN, 2000).

\subsection{O IDOSO E O "TORNAR-SE AVÔ"}

Oliveira et al. (2010) apontam que ser avó é uma arte, observada como um enfoque beneficiado da capacidade de ser pais de filhos adultos, compartilhando sugestões e experiências. Tais filhos adultos admitem esta experiência quando também se tornam avós. Quando essas gerações se aproximam, obstáculos são rompidos, preconceitos extintos e as diferenças são eliminados. O tornar-se avô não é uma questão opcional. Possivelmente tem início aos trinta anos de idade, evidenciando que não há uma idade certa para isso acontecer. Sendo assim, conviver e lidar com o vínculo terno que surge com os netos possibilita um relacionamento mais livre e dinâmico, destacando a magnitude que essa relação pode positivamente lograr êxitos no conforto da existência. Esse vínculo afetivo pode salientar uma função muitas vezes materna ou paterna, porém, propõe ao idoso desenvolver uma responsabilidade singular, com a concepção de distinguir a função entre pai e mãe, da de avô e avó nessa relação com os netos.

No Brasil, considerando o aspecto cultural, especificamente, em muitas regiões, tem-se o hábito de chamar de "tia" ou "tio" pessoas próximas do convívio social, como no caso da professora e funcionários da escola, ou até mesmo parentes distantes ou de outras crianças. Esse costume também se aplica às pessoas idosas, em que são chamadas de "vovô" ou "vovó", por serem pessoas mais velhas, embora não se retratando de pessoas do vínculo consanguíneo.

Segundo Oliveira et al. (2010), o olhar sobre o idoso tem passado por mudanças, tanto pela ótica social, quanto pela familiar. Cresceu a quantidade de avós e o número de anos que esses indivíduos permanecem como avós. A avosidade é um termo pouco conhecido, que surgiu diante de uma análise biológica ultrapassando a cronológica. Esse termo explicita uma ligação de parentesco sanguíneo ou não, está profundamente conectada às atribuições maternas e paternas, demandando do idoso uma 
reorganização psíquica, no sentido de que haja a transmissão de afeto. Tal posição assume, muitas vezes, um papel divergente da função do pai, dando ao idoso lugar pessoal dentro do meio familiar e fora dele (OLIVEIRA et al., 2010).

Mesmo que ainda prevaleça uma percepção preconceituosa em relação aos avós atualmente, no sentido de imaginá-los como idosos, improdutivos, beneficiários da previdência social, restritos a serviços domésticos, há outras percepções que têm ressignificado essa visão estigmatizada. Pois muitos idosos continuam no mercado de trabalho, mantendo-se financeiramente não sendo dependentes dos filhos e/ou dos netos (OLIVEIRA et al., 2010).

Crespo (2011) afirma que, nos últimos anos, envelhecer concatenou-se a imagens negativas, pela valorização de uma eterna juventude em detrimento de uma valorização da velhice. A mídia contribui significativamente para reforçar esse destaque da juventude como a melhor fase. A evidência da juventude, enfatizando a aparência física boa e um condicionamento saudável, afeta a percepção da velhice que é percebida como uma fase predominantemente de desgaste físico e declínio mental, como também falta de planos futuros e desejo de se continuar vivendo, muitas vezes estimulando à solidão e ao desinteresse, por parte das pessoas idosas.

O idoso carece de atenção para ser ouvido, uma vez que entende que os filhos não cedem um momento para haver uma conversa. O idoso opta por isolar-se, se limita a determinados comportamentos, perde o interesse pela vida, sente-se desolado, gerando sofrimento. Tais condições podem acarretar em uma depressão, derivada da ausência de diálogo e, consequentemente, de afeto. A maneira que esse idoso é percebido na sua família retrata as alterações na sua personalidade, até mesmo sua figura como avô, afetando a avosidade propriamente dita. Em contrapartida, essa relação afetiva com os netos pode servir como válvula de escape nessa situação, no sentido de resgatar esse idoso do isolamento social e a possibilidade de uma retração desse lugar de isolamento (OLIVEIRA et al., 2010). Durante a infância o contato dos avós com os netos é monitorado pelos pais, especialmente para os netos que moram longe de seus avós. Isso pode implicar na relação, pois quando se encontram os momentos juntos entre avós e netos, é repleto de diversão e satisfação de brincar uns com os outros, ressaltando que, quando os netos crescem, o relacionamento vai se modificando, podendo assumir outros significados importantes. (OLIVEIRA et al., 2010). 


\title{
2.5 PAPÉIS DOS AVÓS
}

A imagem dos avós, tradicionalmente, se caracterizava por indivíduos de passos lentos, de pele enrugada, cabelos brancos, sentados em cadeiras de balanço contando histórias. $\mathrm{O}$ avô era visto como um sujeito retraído ou autoritário, já a avó era tida com uma senhora gentil, sempre disposta a ajudar seus netos. Nos dias de hoje, os papéis desempenhados pelos avós na sociedade e, até mesmo dentro da família, passou a ser mais reconhecido, dentre tantos, cuidar netos é um dos mais evidentes.

\begin{abstract}
Durante a infância um dos espaços de maior circulação das crianças é a casa dos avós: nela os netos despendem grande parte do seu dia a dia, vivenciando experiências significativas de socialização. Quando não estão na escola, é muitas vezes sob o cuidado dos avós que brincam, desenvolvem temas escolares e realizam tarefas. Mais que isso, durante a primeira infância, quando os pais trabalham fora do ambiente doméstico e muitos meninos e meninas não têm acesso a instituições de Educação Infantil, os avós constituem-se como um recurso familiar importante na guarda das crianças, ensinando-lhes as primeiras palavras, as primeiras letras e os primeiros passos. Por isso, os avós não são apenas 'representantes da família' das crianças: eles são figuras centrais, que contribuem diretamente para o seu crescimento e desenvolvimento (RAMOS, 2014, p. 782).
\end{abstract}

Diante desse contexto, as relações entre avós e netos podem trazer benefícios para ambos, principalmente por não ser um relacionamento complexo se comparado à relação entre pais e filhos, cheio de responsabilidades ou obrigações. Para os avós é a esperança da continuidade, pois já passaram tantos aprendizados para seus filhos e, nessa fase, oferecem vários papéis ao se tornarem avós. Já para os netos, a relação com os avós significa uma representatividade de educação e afeto diferentes, pois os avós são mais disponíveis para brincadeiras e passeios, o contrário dos pais que trabalham o dia todo e não têm tempo. Mas, como afirma Sousa (2006), diferente do papel dos pais, o dos avós é estruturado de maneira frequente em cada conjuntura familiar, ou seja, o papel destes é exercido de formas variáveis, como o de assumirem o papel de pais uma vez que estes são ausentes. Contudo, esta experiência não condiz com a mesma responsabilidade que tinham quando criavam seus filhos, pois com os netos não lhes é cobrado o papel de educar e sim de transmitir conhecimentos através de suas histórias.

Dentro desse contexto, os avôs e avós assumem diversas maneiras de desempenhar suas funções. Sendo assim, Neugarten e Weisnstein (1968, apud SOUSA, 2006), destacam cinco estilos de papéis dos avós: (I) os formais, que buscam agir considerando uma forma de ser correto o papel dos pais, ou seja, recusam-se a criar os netos, não aconselhando seus filhos sobre como criá-los; (II) os divertidos, costumam 
ser lúcidos e informais, brincando com seus netos, tornando-se afetivamente amigos, desenvolvendo uma relação mútua; (III) os substitutivos, assumem a responsabilidade de cuidar e educar na ausência dos pais (em casos de morte ou negligência), transformando-se em pais de netos; (IV) os autoritários, utilizam um modelo aceito pelos filhos, ultrapassando o papel autoritário dos pais, até se subordinando a estes; e (V) os distantes, aqueles que só mantêm contato com seus netos em festas e confraternizações da família. Esses estilos de papéis adotados pelos avós estão relacionados ao estado de saúde desses idosos, a distância que moram dos netos, a idade, a personalidade de cada um e o relacionamento que eles têm com os filhos, pois um idoso com a saúde prejudicada é mais propicio a ser um avô formal do que os mais novos e saudáveis, que são mais propensos a serem divertidos. Já os que moram distantes dos netos tendem a prevalecer numa relação mais ausente de afeto e comunicação (SOUSA, 2006).

Independente do estilo que os avós adotam, Kivnick (1982 apud SOUSA, 2006) cita cinco tarefas educativas executadas por eles: (a) mimar, que é diferente de deseducar os netos, trata-se de aproveitar o tempo para brincar e deixar que os netos façam algo que gostam de fazer e que os pais não deixam; (b) favorecer o desenvolvimento do neto; (c) operar como um recurso de sabedoria para os netos; (d) conviver com uma sensação de continuidade pessoal, cujas recordações vão permanecer e que as novas gerações darão continuação a família; e (e) relembrar momentos educativos, a satisfação de reviver suas experiências como pais, através das relações com os netos.

Trazendo para uma perspectiva mais prática, os papéis executados pelos avós que os netos mais apreciam, são: (a) o historiador da família (sempre tem uma história boa pra contar, isso liga o presente ao passado); (b) o professor (sempre tem algo a ensinar); (c) o mentor (vai além de transferir conhecimentos, aguçam a imaginação); (d) estudante (capazes de aprender com netos); (e) parceiro (está sempre disposto a se divertir com netos); (f) gênio (significa que os avós sempre realizam os desejos dos netos); (g) herói (visto como alguém corajoso e capaz de tudo pelos netos); (h) modelo de papel (atitudes, posicionamentos, postura) (KORNHABER, 1996 apud SOUSA, 2006).

Sendo assim, os netos tendem a estabelecer uma relação mais próxima dos avós do que com os próprios pais, pois essa aproximação afetiva proporciona benefícios 
para ambos, pois possibilita à criança o conhecimento dos históricos familiares, visto que os avós costumam falar de forma dinâmica sobre o passado da família. Desse modo, esse vínculo beneficia os avós a lidarem com seu presente, possibilitando relação mais livre sem muitas preocupações.

O papel do avô na sociedade contemporânea é essencialmente maternal, o que contrasta com papel masculino instrumental que ele tem desenvolvido ao longo da vida. Alguns fazem essa transição suavemente, outros com dificuldade. A cultura, porém, fornece apoio, incorporando "status" e respeito a esse papel, facilitando que os avôs possam desenvolver o lado mais maternal sem constrangimento (NYE; BERARDO, 1973 apud DIAS, 2002, p.35).

Os avôs deixaram a postura de autoritários ou retraídos e desenvolveram relações mais afetuosas com seus netos, rompendo preconceitos, aderindo vínculos mais prazerosos, amigáveis e calorosos, pois são sabedores de que os momentos que têm disponíveis com os netos, são temporários e interrompidos. No caso das mulheres-avós, Harper et al. (2004 apud HARPER, 2006) afirma que elas se denominam mais protetoras e parceiras na substituição dos pais, no sentido que sabem mais ouvir, facilitar, referência de disciplina e ensinamentos. As avós são vistas com o pilar familiar, alguém que transmite valores e sabedoria de vida.

\section{MÉTODO}

Trata-se de revisão narrativa de literatura, em que foi realizada uma pesquisa bibliográfica, a qual consiste investigar as relações entre avós e netos, suas características entre os tipos de família e no meio social, compreendendo também os aspectos do envelhecimento. A pesquisa foi realizada com base em publicações de livros encontrados no acervo da biblioteca da Universidade CEUMA; 21 (vinte e um) artigos científicos selecionados em bases de dados eletrônicos. A busca dos artigos científicos utilizados neste trabalho foi realizada nas seguintes bases de dados: Google Acadêmico, SciELO, PEPSIC, BVS - Biblioteca Virtual de Saúde, tendo sido utilizada as seguintes palavras como descritores: "relações entre avós e netos", “envelhecimento", "relações familiares", “idosos no meio familiar", "papel do idoso". Foram escolhidos trabalhos publicados entre os anos de 2000 a 2015.

Os trabalhos foram selecionados diante da leitura dos resumos e por meio dos seguintes critérios: informações verídicas e na integra que atendiam ao tema estudado; publicação em português e dentro do período indicado. Posteriormente, foi feita uma 
análise dos dados, considerando o ano de publicação, o objetivo, a metodologia, o título dos periódicos e os respectivos resultados, para que possibilitasse uma sistematização de ideias por avaliação de relevância ao tema.

\section{RESULTADOS E DISCUSSÕES}

$\mathrm{O}$ aumento da longevidade permite que os idosos tenham uma convivência mais duradoura de três ou mais gerações, conduzindo os idosos a se envolverem mais com a vida familiar. Com isso, os avós vêm ganhando uma representatividade significativa, independente de qual papel desempenham em seu seio familiar, podendo assim, assumirem papel de destaque na vida dos netos. O convívio frequente entre avós e netos resulta no fortalecimento dos vínculos, até porque a relação intergeracional traz boas vantagens. Os idosos melhoram a qualidade de vida, fisicamente se sentem mais ativos, se preocupam com a saúde para que possam garantir o acompanhamento do crescimento das crianças.

Constatou-se que os vínculos afetivos existentes entre pais e filhos são de suma importância para o desenvolvimento emocional da criança desde o momento do nascimento. Porém, foram verificadas que as relações entre pais e filhos podem ser conflituosas por falta de afetividade ou do não cumprimento do dever de cuidar dos filhos/netos (OLIVEIRA et al., 2010). Observou-se que os netos retratam a continuidade genética da família, e que os avós representam a antecipação do futuro. Isso possibilita troca de ideias e de histórias. Nessa relação, foi analisado, de modo geral, que os netos beneficiam muito os avós, uma vez que estes se adaptam a um ambiente diferente, com maneiras diversas de pensar e as quais, consequentemente, aumentam suas capacidades.

Em relação ao papel dos pais, foi constatado que, por conta do ritmo de vida que têm, devido ao trabalho fora, faz com os avós estejam mais propensos a conviver, cuidar e educar seus netos. Acreditam que assumindo os cuidados dos netos, tornam-se pais pela segunda vez. Além disso, por terem cuidado, preocupação, responsabilidade e afeto pelos filhos quando estes eram crianças, sentem-se na obrigação de repassarem o mesmo para os netos (SOUZA, 2015). O meio familiar consegue designar os aspectos comportamentais do idoso. Desse modo, numa família bastante harmoniosa, em que impera um clima favorável e harmônico entre os seus respectivos membros, possibilita o engrandecimento dos envolvidos. A inserção do idoso no seio da família evidencia uma variedade de funções, 
espaços e condutas, bem como a ocorrência de divergências que estes apresentam são eminentes e consagradas nesse espaço de convívio familiar.

Diante do aumento da longevidade, os idosos passaram a não só conviver mais tempo com seus descendentes, bem como passaram a exercer diferentes papéis na dinâmica familiar. Assim, a velhice passou a ocupar um novo lugar. Apesar da ideia de exclusão e de fragilidade associadas à velhice, além do apoio financeiro, o idoso pode ser uma figura de referência parental tanto para seus filhos, como para seus netos (OLIVEIRA, 2010 apud PINTO et al., 2014). Nesse sentido, o reconhecimento do elo existente entre os avós, pais e filhos adolescentes identifica de que modo essa relação é instituída especificamente com avós e netos. Esse elo enfatiza a delicadeza que essa função requer da parentalidade, na ausência do pai ou da mãe. Sendo assim, os avós lideram uma função primordial, na qual, em muitos momentos, são vistos como elementos de apoio em casos de divórcios ou não, seja por meio da oferta de apoio social ou afetivo.

Igualmente, contudo, os avós exercem também uma principal referência para a família durante as etapas iniciais de um grupo familiar, ou seja, quando seus próprios filhos constituem suas respectivas famílias. Em muitos casos, essa referência volta à vida dos filhos adultos, em especial nos casos em que ocorrem divórcios e separações nas suas famílias. Nesse sentido, Coutrim (2006 apud OLIVEIRA, 2011) afirma que há uma circunstância conhecida como o "efeito bumerangue". Neste efeito, há modificações nas relações entre avós, pais, filhos e netos. Por exemplo, os filhos se casam e passam a residir em outra casa; porém, depois de se divorciarem, voltam a morar com os pais novamente, na busca do apoio emocional ou financeiro. Há casos em que essa volta para a casa dos pais aproxima o relacionamento dos avós com os netos, aprimorando a afetividade.

Durante o tempo da infância dos netos, a aproximação dos avós é monitorada pelos pais, principalmente por uma questão de distância geográfica. Durante esse tempo, esse convívio tende a ser marcante pelo envolvimento afetivo, pela satisfação e pelo divertimento, bem como, à proporção que os netos tornam-se adolescentes, jovens e adultos, apresentam comportamentos significativamente diferentes, que podem alcançar uma determinada importância, pois são responsáveis por optar pelo convívio com seus avós, na medida em que não são mais dependentes dos pais. No Brasil, Debert e Simões (2006 apud PINTO et al., 2014) especulam dois perfis 
de família, caracterizando-as pela presença ou não de pessoas idosas; as famílias de idosos e as famílias com idosos. A primeira reconhece o idoso como líder de família, estando financeiramente responsável pela criação dos netos. Já o segundo perfil é definido por famílias também em que os idosos estão inseridos, mas a condição financeira é baixa, cuja sua função especificamente é a de assistência afetiva cuidando dos netos, em razão de estarem financeiramente dependentes dos filhos.

Por outro lado, Oliveira (2011) enfatiza que os avós e os netos tornam-se mais independentes quando não residem juntos numa mesma casa. Isto resulta numa função diversificada. Em contrapartida, quando moram todos juntos numa mesma residência, esses avós tendem a desempenhar mais as responsabilidades da função paterna. Esse contato regular pode refletir numa relação desorganizada de papéis sociais, em que os avós podem assumir a posição dos pais, camuflando sua figura como avós. Cuidar de netos não significa somente experiências agradáveis, mesmo que isso ocorra de forma voluntária. Por outro lado, os avós que só cuidam dos netos quando eventualmente são procurados para isso, sem se comprometer com as responsabilidades desse lugar dos pais em relação à educação dos filhos/netos evidenciam relações afetivas com menor intensidade de estresse. Embora, no momento que os pais se ausentam, os avós acabam assumindo essa posição de cuidadores ou de pais sucessores eventualmente.

Para Attias et al. (2001 apud CARDOSO et al., 2014), as tarefas exercidas pelos avós de cuidar dos netos, sem essa transferência de responsabilidade de educar dos pais passando para os avós pode garantir uma estabilidade nos papéis sociais para a família. Especificamente, nesses momentos os avós, em determinadas circunstâncias, se permitem aderir às responsabilidades de cuidado dos netos, tirando dos pais essa obrigação eventualmente. Assim, contribuindo para uma harmonia familiar e reforçando a importância do papel dos avós na educação dos filhos e netos.

A figura do idoso sofreu modificações tanto no meio familiar quanto no social. Sendo assim, aumentou o número de avós e o tempo que permanecem como avós. Como já foi citado na revisão de literatura sobre o termo avosidade, Pedrosa (2006, apud PINTO et al., 2014) afirma que esse termo surgiu a partir dos estudos sobre Psicogerontologia feitos por Paulina Redler, em 1977. A partir disso, sugeriram uma ampliação da questão biológica para além da cronológica, ou seja, quando o idoso ocupa uma nova posição pessoal, familiar ou social, sendo avô e/ou avó, necessita de 
uma restruturação psíquica, e assim, realçar seus laços de parentesco. Avosidade não se remete somente a idosos acima de 60 anos, ou seja, não está ligada a idade cronológica, e sim às funções materna e paterna, sinalizando uma grande importância para o desenvolvimento do sujeito. Portanto, os netos assumem um papel importante na vida daqueles que estão envelhecendo.

Monteiro (2015) descreve o ser avô como uma função que, dentro da avosidade, pode se produzir independente de idade ou vínculo consanguíneo, ou seja, basta duas pessoas exercerem os papéis de avós, implicando numa relação trigeracional entre avós, filhos e netos. Essa relação de afeto pode desencadear antes do nascimento e continuar após. Nesse momento, os avós são dominados pelo sentimento materno/paterno, se disponibilizando a sentir e reviver as experiências e sensações de quando seus filhos estavam sob seus cuidados. O idoso quando se torna avô, vira um marco na sua história de vida dos netos e envolve todos os membros da família. Ser avó é de caráter relativo, subjetivo e interpessoal. Ser avó também põe o idoso em contato com a velhice, causando pensamentos sobre seu processo de envelhecimento. Isso costuma acontecer após o nascimento do neto e, como qualquer outra relação, é comum haver sentimentos dúbios, como amor e desejo, rivalidade e hostilidade (MONTEIRO, 2015).

\section{CONSIDERAÇÕES FINAIS}

O envelhecimento populacional é um fenômeno nacional e mundial que demanda da sociedade contemporânea novos conhecimentos acerca das relações entre avós, filhos e netos. Aquela imagem mantida tradicionalmente, cujos avós ficavam sentados em cadeiras de balanço e ociosos a maior parte do dia, muitas vezes contemplada na literatura infantil, tem se modificado ao longo dos últimos anos, sendo substituídas por avós ativos e que têm assumido papéis diferenciados na vida dos netos. As relações entre avós e netos, e os papéis desempenhados por esses idosos dentro do seio familiar, adquirem cada vez mais reconhecimento social, despertando interesse dos pesquisadores acadêmicos e cientistas na área da Psicologia e Gerontologia. Nesse sentido, esta pesquisa contemplou um estudo sobre esses vínculos afetivos entre avós, netos e família.

Este trabalho possibilitou compreender um pouco mais sobre os idosos, teve como foco de pesquisa estudar essas relações existentes entre as várias gerações no 
meio familiar e social, levando em consideração a problemática da ausência de comunicação adequada com os filhos. No decorrer deste artigo, foram discutidas e conceituadas questão do processo do envelhecimento humano, enaltecendo o idoso como avô e papel que ele representa no âmbito familiar. A literatura apontou que essas relações entre avós e netos caracterizam um novo arranjo familiar com avós mais modernos, onde esses vínculos resultam em benefícios para ambos. Destacou, ainda, que esses idosos sentem-se incluídos, válidos e capazes.

\section{REFERÊNCIAS}

ALMEIDA, S. E. M. Uma proposta sobre a transgeracionalidade: o absoluto. Ágora v. XIII n. 1 Rio de Janeiro, 2010. Disponível em: http://www.scielo.br/pdf/agora/v13n1/07.pdf Acesso em: 23 de outubro de 2016.

ASSIS, M. Envelhecimento ativo e promoção da saúde: reflexão para ações educativas com idosos. Revista APS, v8, Rio de Janeiro, 2005. Disponível em: http://www.ufjf.br/nates/files/2009/12/Envelhecimento.pdf Acesso em: 30 de outubro de 2016.

BRASIL. Dados sobre o envelhecimento do idoso. Secretária dos direitos humanos SDH. Secretaria nacional de promoção defesa dos direitos humanos. Presidência da República. Brasília - DF, 2003. Disponível em: http://www.sdh.gov.br/assuntos/pessoaidosa/dados-estatisticos/DadossobreoenvelhecimentonoBrasil.pdf Acesso em: 14 de outubro de 2016.

CARDOSO, A. R.; BRITO, L. M T. Ser avó na família contemporânea: que jeito é esse? Psico-USF, Bragança Paulista, v. 19, n. 3, p. 433-441, 2014. Disponível em: http://www.scielo.br/pdf/pusf/v19n3/07.pdf. Acesso em: 29 de maio de 2016.

CRESPO, V. L. Os idosos e seus tempos de lazer em família: uma aproximação pedagógica-social. Estud. interdiscipl. envelhec., Porto Alegre, v. 16, edição especial, p. 341-353, 2011. Disponível em: http://bvsalud.org/. Acesso em: 30 de maio de 2016.

DIAS, B. S. M. C. A influência dos avós nas dimensões familiar e social. Recife-PE, 2002. Disponível em: http://www.maxwell.vrac.puc-rio.br/5743/5743.PDF Acesso em: 28 de outubro de 2016.

HARPER, S. Papéis dos avós nas famílias multigeracionais dos nossos dias. Revista povos e culturas, 2006. Disponível em: http://www.fch.lisboa.ucp.pt/resources/Documentos/CEPCEP/POVOS\%20E\%20CULT URAS_10.pdf Acesso em: 31 de outubro de 2016.

KIPPER, R. D. C.; LOPES, S. R. O Tornar-se avô no processo de individuação. Psicologia: Teoria e Pesquisa. Porto Alegre - RS, 2006. Disponível em: 
https://www.lume.ufrgs.br/bitstream/handle/10183/20278/000570647.pdf?sequence=1 Acesso em: 15 de outubro de 2016.

JUNG, G. C. Tipos psicológicos. Vozes. Petrópolis, 2009. Disponível em: https://psicoterapiajunguiana.com/conceitos/processo-de-individuacao/ Acesso em: 13 de outubro de 2016.

MONTEIRO, C. E. Avosidade: o exercício da função de avós, as relações e os conflitos. Anais CIEH - Vol. 2, N.1. Fortaleza - CE, 2015. Disponível em: http://www.editorarealize.com.br/revistas/cieh/trabalhos/TRABALHO_EV040_MD2_S A1_ID27_06092015121015.pdf Acesso em: 02 de novembro de 2016.

MORAES. E, N.; MORAES. F. L.; LIMA. S.; P.; P. Características biológicas e psicológicas do envelhecimento. Revista Med Minas Gerais 2010; p. 67-73. Disponível em: http://www.observatorionacionaldoidoso.fiocruz.br/biblioteca/_artigos/197.pdf. Acesso em: 28 de abril de 2016.

NERI, L. A. Contribuições da psicologia ao estudo e à intervenção no campo da velhice. RBCEH - Revista Brasileira de Ciências do Envelhecimento Humano, Passo Fundo, 2004. Disponível em: http://anakarkow.pbworks.com/w/file/fetch/99591271/neri.pdf Acesso em: 14 de outubro de 2016.

NERI, L. A. A velhice bem-sucedida: aspectos afetivos e cognitivos. YASSUDA. M. S. (orgs.). COCHIONI. M. (colab.). Ed. 4ª Campinas, SP: Papirus, 2012.

OLIVEIRA, A. R. V.; VIANNA. L. G.; CÁRDENAS. C. J. Avosidade: Visões de avós e de seus netos no período da infância. Rev. Bras. Geriatria, Gerontologia. Rio De Janeiro, 2010. Disponível em: http://www.scielo.br/pdf/rbgg/v13n3/a12v13n3.pdf. Acesso em: 11 de abril de 2016.

OLIVEIRA, M. R.; de. As relações intergeracionais e a participação dos avós na família dos filhos. 2011. Tese de Doutorado em Processos de Desenvolvimento Humano e Saúde. Universidade de Brasília, Brasília, 2011. Disponível em: http://repositorio.unb.br/handle/10482/18033. Acesso em: 28 de maio de 2016.

PINTO. K. L. B.; ARRAIS. R. A.; BRASIL. R. T. C. K.; Avosidade x maternidade: a avó como suporte parental na adolescência. Psico-USF, Bragança Paulista, v. 19, n. 1, p. 37-47, 2014. Disponível em: http://www.scielo.br/pdf/pusf/v19n1/a05v19n1.pdf. Acesso em: 20 de outubro de 2016.

RABELO, F. D.; NERI, L. A. Arranjos domiciliares, condições de saúde física e psicológica dos idosos e sua satisfação com as relações familiares. Rev. Bras. Geriatr. Gerontol, Rio de Janeiro, 2015.2 Disponível em: http://www.scielo.br/pdf/rbgg/v18n3/1809-9823-rbgg-18-03-00507.pdf Acesso em: 20 de outubro de 2016.

RAMOS, C. A. Sobre avós, netos e cidades: entrelaçando relações intergeracionais e experiências urbanas na infância. Educ. Soc., Campinas, 2014. Disponível em: 
http://www.scielo.br/pdf/es/v35n128/0101-7330-es-35-128-00781.pdf Acesso em: 31 de outubro de 2016.

REHBEIN, P. M.; CHARTELARD, S. D. Transgeracionalidade psíquica: uma revisão de literatura. Fractal, Rev. Psicol., v. 25, Brasília-DF, 2013. Disponível em: http://www.scielo.br/pdf/fractal/v25n3/a10v25n3.pdf Acesso em: 23 de outubro de 2016.

RODRIGUES, V. P. J. Os Avós na Família e Sociedade Contemporâneas Uma Abordagem Intergeracional e Intercultural. Tese de Doutoramento em Psicologia Especialidade Psicologia Intercultural. Lisboa, Portugal, 2013.

SOUSA, L. avós e netos: uma relação afetiva, uma relação de afetos. Revista povos e culturas, n.10, p.inicial-final, 2006. Disponível em: http://www.fch.lisboa.ucp.pt/resources/Documentos/CEPCEP/POVOS\%20E\%20CULT URAS_10.pdf Acesso em: 24 de outubro de 2016.

SOUZA, A. F. Voltando ao tempo: o papel dos avós como guardiões. Baurú - SP, 2015. http://www.unisalesiano.edu.br/simposio2015/publicado/artigo0096.pdf Acesso em: 26 de outubro de 2015.

ZIMERMAN. I. G. Velhice: aspectos Biopsicossociais. Porto Alegre, RS: Artes Médicas Sul, 2000. 